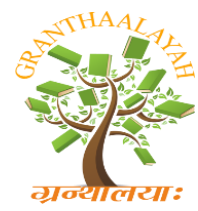

INTERNATIONAL JOURNAL OF RESEARCH GRANTHAALAYAH A knowledge Repository

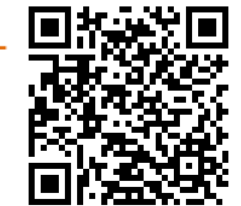

Science

\title{
OPTICAL-ELECTRONIC METHOD FOR AEROSOL PARTICLES MEASUREMENT IN ENVIRONMENT
}

\author{
Ruben Asatryan *1 \\ ${ }^{* 1}$ National Institute of Metrology, ARMENIA
}

\begin{abstract}
The description of the developed by us automatic Multichannel Aerosol Spectrometer "Masnik- $A$ " are presented. "Masnik- $A$ " system represents the optical/electronic automatic device for measuring of the concentrations and distributions of the sizes of liquid and solid aerosol particles of natural and artificial origin in laboratory and field conditions. Aerosol Spectrometer "Masnik- $A$ " provides a range of measurement of the sizes of aerosol particles from 0.5 up to $40 \mathrm{~mm}$ (on a radius). It has 18 channels of the analyzer (graduations by the sizes) with a memory on the channel no less than 9.105 particles. The limiting value of measuring concentrations (containing in $1 \mathrm{~cm} 3$ of the aerosol environment) makes no less 2.104 particles. The instrument has possibility of obtaining the command of handle from external personal computer (PC), and also input of the results of measurements for further automatic processing by a specially developed program.
\end{abstract}

Keywords:

aerosol particle, multichannel aerosol spectrometer, optical/ electronic unit, distant exploiting of instrument.

Cite This Article: Ruben Asatryan, "OPTICAL-ELECTRONIC METHOD FOR AEROSOL PARTICLES MEASUREMENT IN ENVIRONMENT" International Journal of Research Granthaalayah, Vol. 4, No. 4 (2016): 27-30.

\section{INTRODUCTION}

In the sphere ecological researches of atmosphere takes an important place the study of the structural and physical features of the particles of liquid and solid aerosol formations. As they represent danger to normal habitability of man and other biological objects.

The present report is devoted to the representation of working out method, developed by us, and instrumentation of monitoring of an atmospheric aerosol, under a title "Masnik-A". A multichannel aerosol spectrometer "Masnik-A" represent the optical-electronic automatic device for measuring the concentration and distribution of the sizes of liquid and solid aerosol particles of natural and artificial origin in laboratory and field conditions [1], [2]. 


\section{SHORT DESCRIPTION OF EQUIPMENT}

The "Masnik-A" system provides a range of measurement of the sizes of aerosol particles from 0.5 up to $40 \mu \mathrm{m}$ (on a radius). It has 18 channels of the analyzer (graduation by the sizes) with a memory on the channel no less than $9.10^{5}$ particles. The limiting value of measuring concentrations (containing in $1 \mathrm{~cm}^{3}$ of the aerosol environment) makes no less $2.10^{4}$ particles. The instrument has possibility of obtaining the command of handle from external personal computer (PC), and also input of the results of measurements for further automatic processing by a specially developed program.

Structurally the spectrometer "Masnik-A" consists of two units: the optical-electronic unit (OEU), both unit of counting and handling (UCH) with PC, joint among themselves by a cable. OEU is installed immediately in the atmosphere (or in volume) where it is necessary to carry out researches of aerosol particles, and $\mathrm{UCH}$ with a computer can be placed in a premise, or in the auto-laboratory, length of cables between them can be up to $25 \mathrm{~m}$. The optical scheme of the OEU is shown on the Fig. 1.

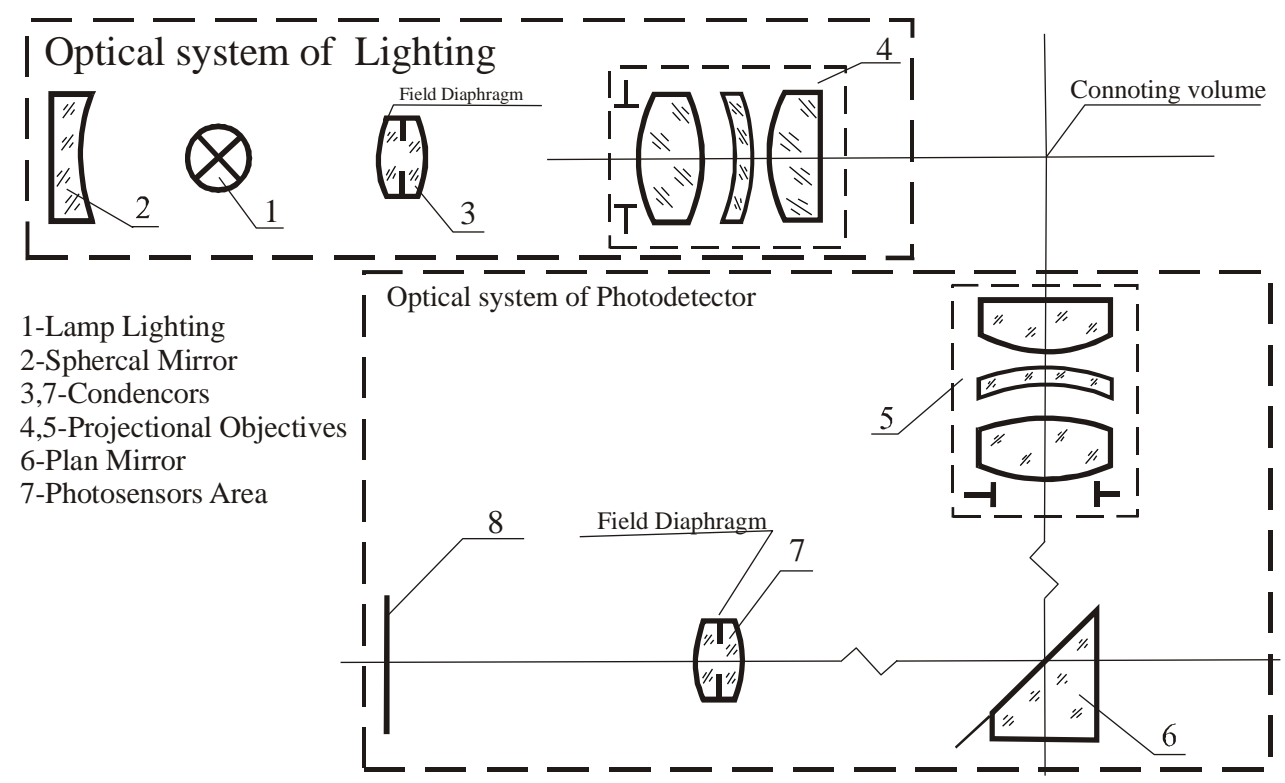

Figure 1: Optical scheme of OEU aerosol spectrometer "Masnik-A".

The principle of the instrument is based on measurement of an emission power, scattered on aerosol particles. At the moment of passing each aerosol particle through countable volume of the instrument at the exit of the photo-detector (PEM-79), there appear are impulse electrical signals, the amplitude of which bears information about the sizes of particles [3].

The optical-electronic Unit consists of three main knots: Knot of Lighting with optics, the knot of the photo-detector with optics and the knot of aspiration, where the measured aerosol environment is soaked up. The main unit of the equipment ensuring reception of the initial information about the dispersion of aerosol particles is Optical Electronic Unit. The OEU consists of system aspiration, optical systems, power unit and preliminary processing of the information. 
The optical systems of lighting and the Photo-detector (see Fig. 1) are intended for optical formation of the counting volumetric space with discrete change of its sizes, which is achieved by replacement field diaphragms, which are put on flat stuck together surfaces condensers.

The optical system of photo-detector is identical to system of the lighting, except that in which absence mirror, and on the location of a body of heat of a light source is located the adopted area of the photo-detector, in quality the photo-electronic multiplier (PEM-79) is used. The optical system of the lighting provides carry of the image of heat of a lump to area of counting volume which is taking place on an axis in taking of the aspiration system. From the aspiration system the jet of aerosol particles is directed to a bunch of the light beams. As a result of it, the aerosol particles getting in the most concentrated area of a light flow, scattered light, which part is going to the objective of the photo-detector system, through its field diaphragms. The field diaphragms of the lighting and the photo-detector systems allow to allocate area of counting volume, within the limits of which there is an analysis of the sizes of aerosol particles and calculation of their quantities. The functional electrical scheme of the aerosol spectrometer is shown on Fig. 2.

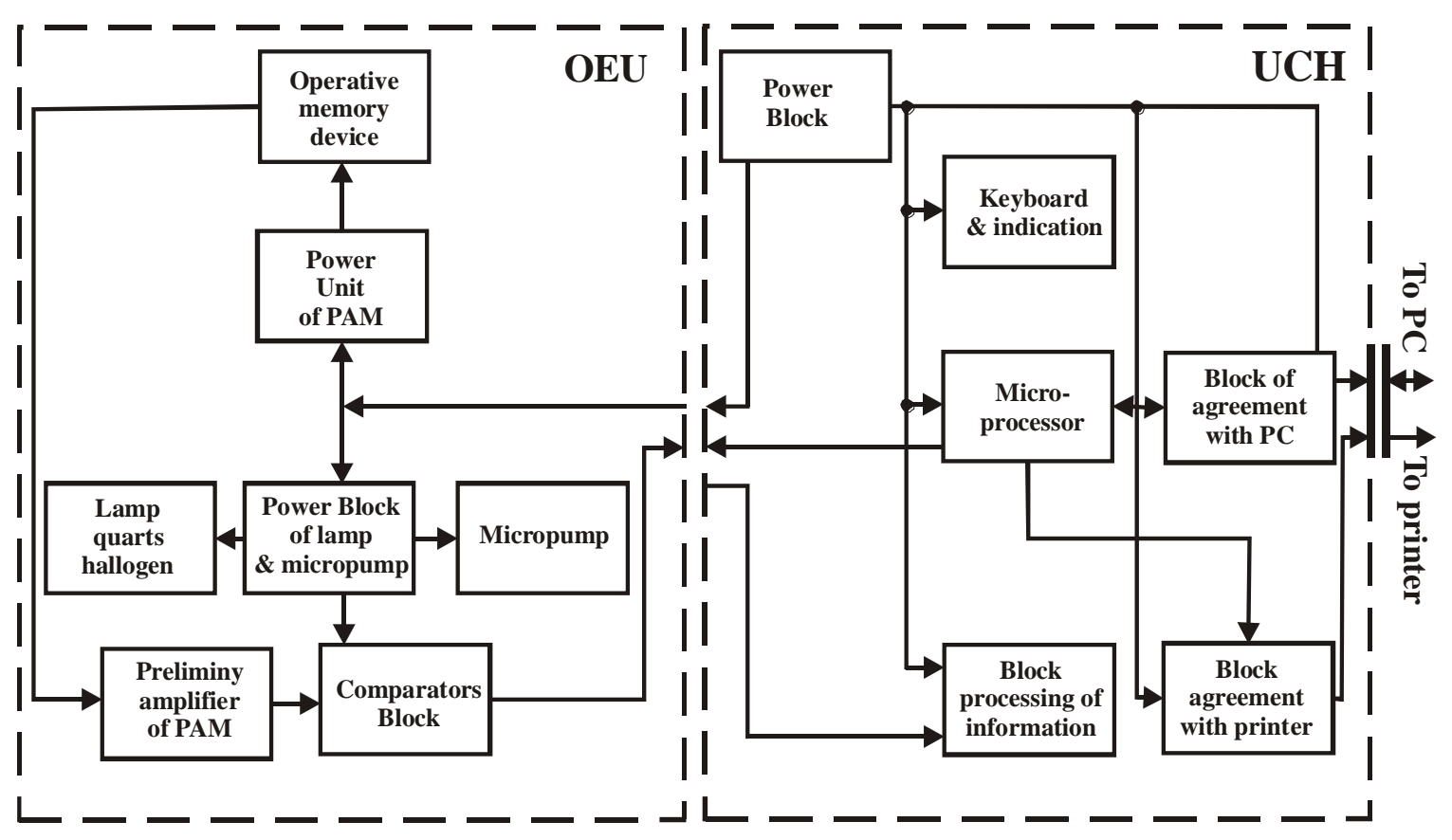

Figure 2: Functional electrical block-scheme of aerosol spectrometer "Masnik A".

The pulse electrical analogous signals, from the photo-detector output amplify and transforms in a five-digit digital code and act to the block of processing of the information, which makes the peak analysis of pulses on 18 channels and registration them in view of the given restriction for discrimination on duration. The microprocessor makes initialization in all functional units of the spectrometer and processing of acting information. The results of measurements of the microprocessor are deduced on indication, and also, at the request of the operator, through the appropriate devices of interface are deduced on a seal and PC. The appearances of the OEU (a) and $\mathrm{UCH}(\mathrm{b})$ are shown on a Fig. 3. 


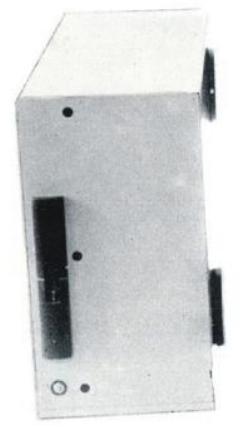

(A)

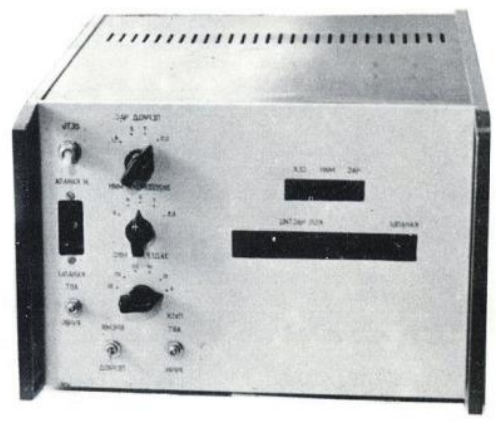

(B)

Figure 3: OEU (a) and UCH (b) aerosol spectrometer "Masnik-A".

Before natural measurements in atmosphere the optical graduation of a spectrometer "Masnik-A" on standard particles of polistirol latex is carry out [4]. The graduation characteristics (i.e. dependence of output signal amplitude from a size of aerosol particle) are introduced in the permanent memory of the system for the further using in automatic processing of the measuring results.

\section{CONCLUSION}

The typical Characteristic feature of the developed by us aerosol Spectrometer is the using of complect changing field diaphragms, limiting the geometrical sizes of the instruments working volume in dependence from measuring counting concentrations of aerosol particles, as also contructions making of instrument is in two units $\mathrm{OEU}$ and $\mathrm{UCH}$, that is provide the distant exploiting of instrument and safety of serving personal.

On the developed by us Aerosol Spectrometer received Patent AM, No 1807 A2, 15.06.2006.

\section{REFERENCES}

[1] R.Asatryan, N.Khachatryan, H.Karayan, Optical-Electronic Automatic System for Aerosol Particles Measurement in Atmosphere, National Assocation of Scientists, Monthly Scientific Journal, No, 4(9), 2015, pp.56-59.

[2] R.Asatryan S. Asatryan L. Vardumyan H. Gevorkyan, Multichannel Aerosol Spectrometer, Instruments and Experimental technics, No ,4, 2004, pp.166-167 (in Russian).

[3] R. Asatryan, S. Asatryan, H.Gevorkyan, H. Karayan, Opticall Electronic System Measuring Solid and Liquid Aerosol Concentrations in Atmosphere, European Aerosol Conf.-2004, September 6-10, 2004, Budapest, Hungary, Abstracts of the European Aerosol Conf.-2004, Published in association with the Journal of Aerosol Science, Vol. 1, 2004, pp. 263-264.

[4] R. Asatryan ., Optical/Electronic Methods of Radioation Fields Analysis, Candidates Deg. Theses, Yerevan State University, pp. 18 2000, (in Russian). 